\title{
High-power picosecond laser drilling/machining of carbon fibre-reinforced polymer (CFRP) composites
}

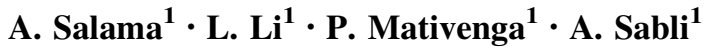

Received: 17 December 2015/ Accepted: 3 January 2016/Published online: 22 January 2016

(C) The Author(s) 2016. This article is published with open access at Springerlink.com

\begin{abstract}
The large differences in physical and thermal properties of the carbon fibre-reinforced polymer (CFRP) composite constituents make laser machining of this material challenging. An extended heat-affected zone (HAZ) often occurs. The availability of ultrashort laser pulse sources such as picosecond lasers makes it possible to improve the laser machining quality of these materials. This paper reports an investigation on the drilling and machining of CFRP composites using a state-of-the-art $400 \mathrm{~W}$ picosecond laser system. Small HAZs $(<25 \mu \mathrm{m})$ were obtained on the entry side of 6-mm-diameter hole drilled on sample of $6 \mathrm{~mm}$ thickness, whereas no HAZ was seen below the top surface on the cut surfaces. Multiple ring material removal strategy was used. Furthermore, the effect of laser processing parameters such as laser power, scanning speed and repetition rate on HAZ sizes and ablation depth was investigated.
\end{abstract}

\section{Introduction}

The increasing use of CFRP composites, because of their unique properties, in a wide range of applications including aerospace, automotive and sport equipment [13] has necessitated the development of effective and lowcost machining processes to process these materials with high quality and efficiency. Machining of CFRP composites differs considerably from machining conventional

A. Salama

adel.salama@postgrad.manchester.ac.uk

1 Laser Processing Research Centre, School of Mechanical, Aerospace and Civil Engineering, The University of Manchester, Manchester M13 9PL, UK metals due to their inhomogeneity properties, heat sensitivity and the carbon fibre being very abrasive [4]. Generally, CFRP composites exhibit various forms of damages during mechanical machining and water jet machining. Such defects include carbon fibre pull-out, delamination, excessive tool wear, abrasive penetration, acoustic noise and abrasive slurry disposal [5-7]. Laser machining as a non-contact process offers several advantages, such as free from tool wear, no contact force-induced problems and no abrasive or liquid media [8,9]. However, the large differences in physical and thermal properties of the CFRP constituents make laser machining challenging. Laser processing of these materials often leads to an extended HAZ, which is considered as the major obstacle for its wide industrial applications. Minimising or eliminating HAZ in the polymer matrix is a major challenge in laser processing of CFRP [10]. Since the HAZ is influenced by the laser-material interaction time, the release of high pulse energy in a very short time, as in the case of ultrashort pulsed laser sources such as picosecond and femtosecond lasers, the laser beam directly evaporates the materials and leaves little time for the heat to propagate to the adjacent substrate, hence limiting the HAZ extension [11].

Various studies have been conducted in order to investigate laser processing of CFRP composites. The influence of different process parameters including laser wavelengths, beam transverse mode, pulse duration, repetition rate, laser power density, fluence (energy density), beam spot size, scanning speed and machining strategy were investigated [5, 9-21]. Li et al. [9] investigated the machining quality of CFRP using a diode-pumped solidstate UV laser. They showed that minimum HAZ $(50 \mu \mathrm{m})$ was achieved using a nanosecond pulsed UV diodepumped solid-state (DPSS) laser cutting at a very high 
scanning speed $(800 \mathrm{~mm} / \mathrm{s})$. They introduced a new drilling/machining strategy by using multiple rings in order to widen the cut kerf for more effective material removal. They also suggested that short laser-material interaction time such as short pulse and high scanning speed is needed to reduce HAZ. The development in laser technology and the presence of ultrashort laser pulsed sources such as picosecond lasers opened new opportunities and make it is possible to improve the laser machining quality for processing CFRP. It was found [19-21] that ultrashort pulse lasers using picosecond systems could produce smaller thermal damages. Finger et al. [11] have recently investigated the processing of 2-mm-thick CFRP composite sample using a picosecond pulsed laser with an average power of up to $80 \mathrm{~W}$. They also evaluated the influence of average power, scanning speed and repetition rate on the ablation rate and the width of HAZ. They showed that PS laser processing of CFRP with a $\mathrm{HAZ}<5 \mu \mathrm{m}$ and an ablation rate of $100 \mathrm{~mm}^{3} / \mathrm{min}$ could be obtained.

This paper reports an investigation on drilling of CFRP using a state-of-the-art $400 \mathrm{~W}$ picosecond laser system. The effect of laser parameters such as laser power, scanning speed and repetition rate on HAZ and ablation depth was investigated.

\section{Experimental details}

\subsection{Experimental set-up and materials}

The laser milling and drilling experiments were performed using a picosecond laser system. The machine specifications are given in Table 1. CFRP composites plates of 1,2 and $6 \mathrm{~mm}$ thicknesses were used as the workpiece materials. The laser beam was delivered to the workpiece by means of a three-axis galvanometric scanner head with an f-theta focusing lens, which allowed the scanning of the laser beam with the same beam size and orientation across the scanning plane. An Aerotech computer-controlled $x-y$ stage was used to mount the sample and for initial

Table 1 Picosecond laser system specifications

\begin{tabular}{ll}
\hline Parameters & Specifications \\
\hline Operating mode & Pulsed \\
Wavelength & $1064 \mathrm{~nm}$ \\
Maximum average power & $400 \mathrm{~W}$ \\
Repetition rate & $0.5-20 \mathrm{MHz}$ \\
Pulse length & $10 \mathrm{ps}$ \\
Focal length & $330 \mathrm{~mm}$ \\
Max. galvo-scanning speed & $10 \mathrm{~m} / \mathrm{s}$ \\
Spot size at focus & $125 \mu \mathrm{m}\left(1 / \mathrm{e}^{2}\right)$ \\
\hline
\end{tabular}

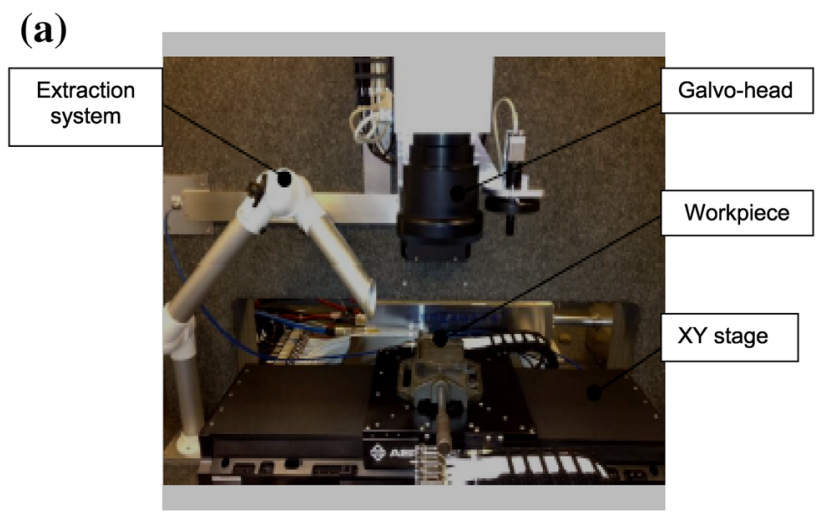

(b)

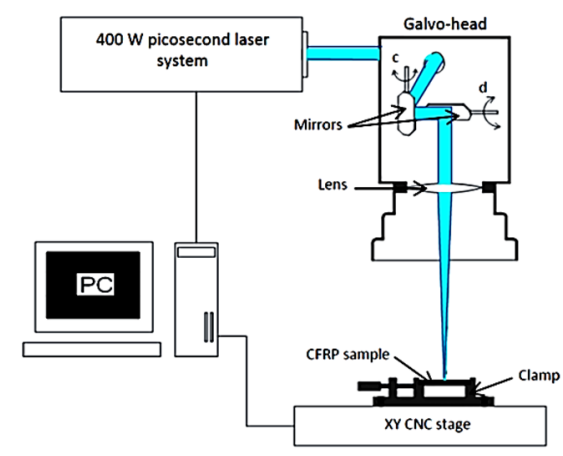

Fig. 1 Experimental set-up; a machine's stage/galvo-head, b schematic diagram of experimental set-up

positioning of the experimental sample within the galvoscanning zone. The galvo-head can be moved upward and downward in the $Z$ axis which permits the adjustment of the focal plane position initially on the upper surface of the workpiece. Figure 1 shows the basic experimental set-up. All the experiments were carried out at a pulse frequency of $0.5 \mathrm{MHz}$, and the average powers were varied from 6 to $30 \mathrm{~W}$.

\subsection{Experimental procedure}

As the initial experimental investigations showed that using a single-ring trepanning strategy for drilling 6-mmthick sample could deteriorate the machining quality considerably due to high heat accumulations, the experiments were performed using a multi-ring strategy (Fig. 2) by removing the material layer by layer with a wide kerf (ring width) to facilitate better material ejection from the beam/material interaction zone and reduce the shielding of incident laser beam by the plume generated. The focal plane was first set at the sample's upper surface at the beginning of the drilling; then, it moved down by $0.25 \mathrm{~mm}$ for each set of 100 passes. Multi-ring drilling starts from the hole's outer diameter to create a trench to block the additional energy input generated by the internal rings from transferring along the fibres to the surrounding bulk 
Fig. 2 Schematic of multi-ring strategy used for laser drilling of CFRP

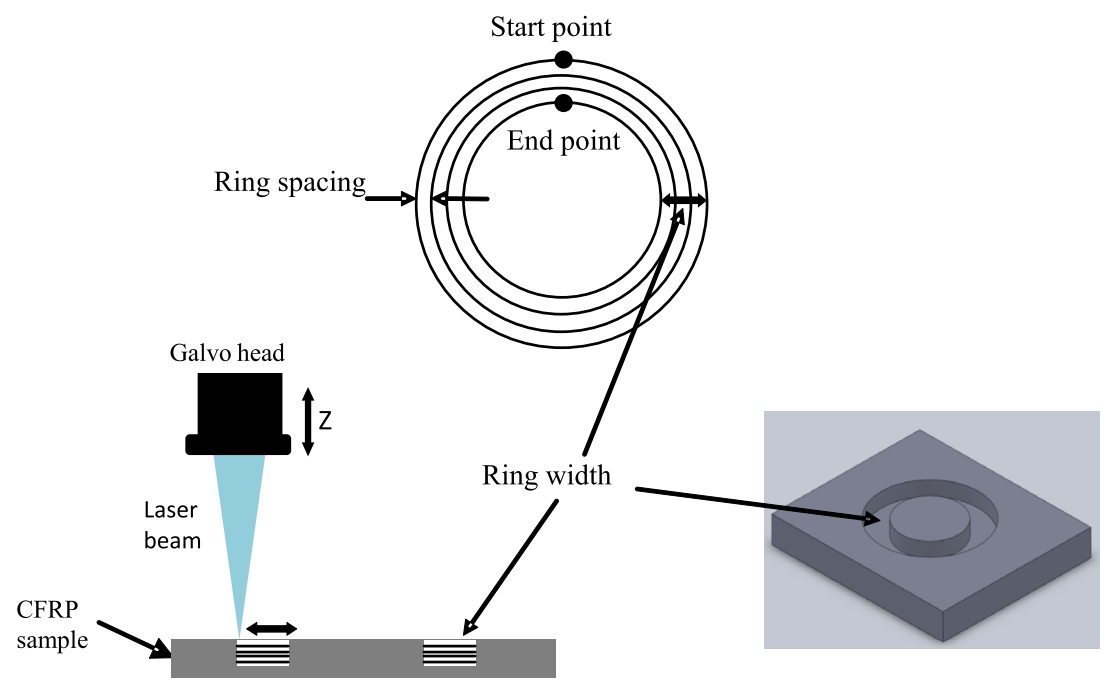

material. Furthermore, the effect of laser process parameters, i.e. laser power, scanning speed, repetition rate and ring spacing on ablation depth and HAZ, were investigated in this work. The size of the HAZ and cutting quality were studied using optical microscopy and scanning electron microscopy (SEM). The HAZ was characterised by measuring the length of fibres extruding out of the matrix and recession of the matrix.

\section{Results}

The ablation rate $(d)$ dependence on the laser fluence $F(\mathrm{~J} /$ $\mathrm{cm}^{2}$ ) based on Beer-Lambert law, Eq. (1), is shown in Fig. 3, where a linear relationship between the ablation depth per pulse and the ln of laser fluence is shown experimentally. The ablation depth is typically between 2 and $15 \mathrm{~nm} /$ pulse. This is much smaller compared with those by nanosecond and millisecond laser pulses.

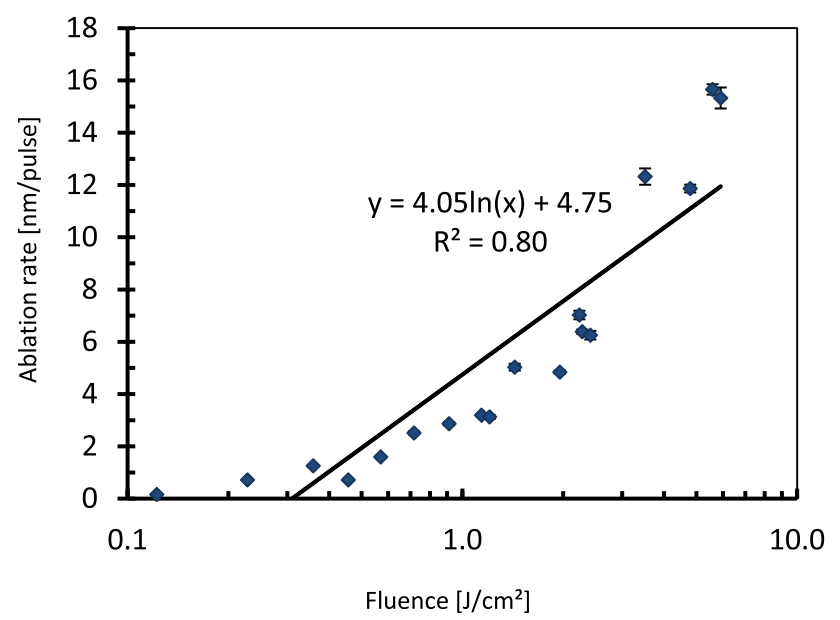

Fig. 3 Ablation rate dependence on laser fluence $d=\frac{1}{\alpha} \ln \left(\frac{F}{F_{\mathrm{th}}}\right)$

where $\alpha$ the absorption coefficient $\left(\mathrm{cm}^{-1}\right), F$ the laser fluence (energy density) and $F_{\text {th }}$ the threshold fluence. Using curve fitting, $\alpha$ and the threshold fluence can be calculated. Moreover, the thermal loading $\gamma\left(\mathrm{J} / \mathrm{cm}^{3}\right)$ of the CFRP can be calculated by [22]:

$\gamma=F_{\text {th }} \times \alpha$

A threshold fluence of $0.3 \mathrm{~J} / \mathrm{cm}^{2}$, absorption coefficient of $0.25 \mathrm{~nm}^{-1}$, optical penetration depth of $4 \mathrm{~nm}$ and thermal loading of $741 \mathrm{~kJ} / \mathrm{cm}^{3}$ were obtained using Fig. 3 and Eqs. (1) and (2).

\subsection{Effect of laser power and scanning speed on HAZ and ablation depth}

Figure 4 shows that the material removal depth per pass is reduced as the scanning speed increases, whereas the

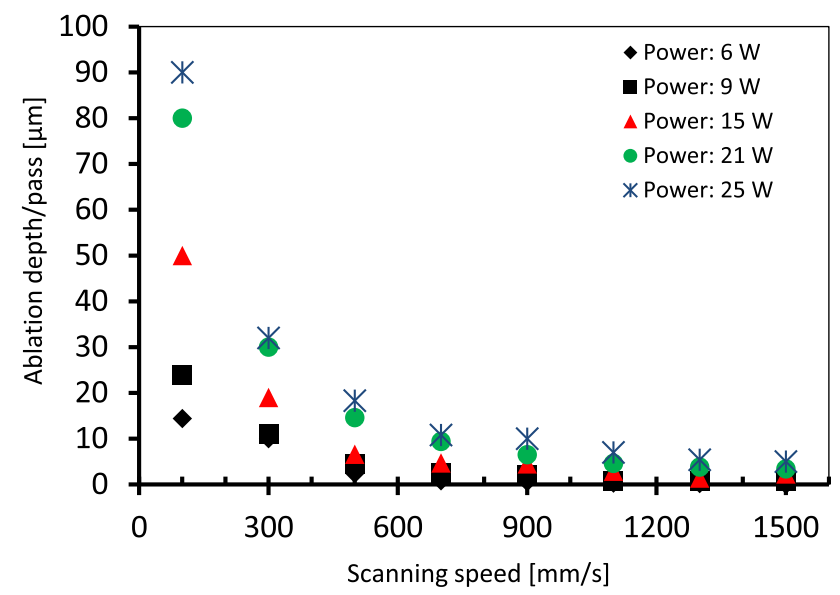

Fig. 4 Effect of scanning speed on ablation depth 
Fig. 5 Effect of power/speed on HAZ and ablation depth

Laser power

High depth/HAZ
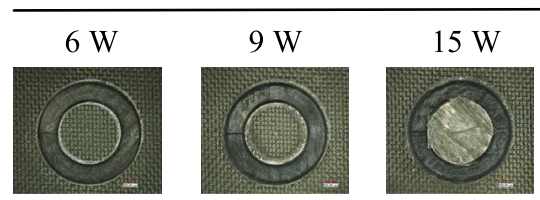

$\mathrm{HAZ}=219$

- Sample thickness: $6 \mathrm{~mm}$

- Diameter: $6 \mathrm{~mm}$

- Repetition rate: $0.5 \mathrm{MHz}$

- Number of passes: 10 (for speeds 100, 300)

- Number of passes: 50 (for other speeds)

- No dwell
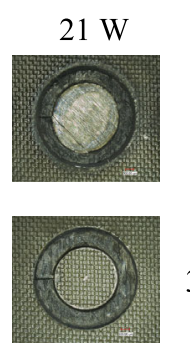

\section{$\mathrm{HAZ}=269 \mu \mathrm{m}$}

$300 \mathrm{~mm} / \mathrm{s}$

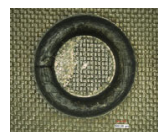

$500 \mathrm{~mm} / \mathrm{s}$

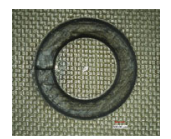

$700 \mathrm{~mm} / \mathrm{s}$

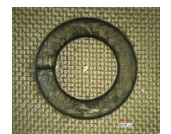

$900 \mathrm{~mm} / \mathrm{s}$

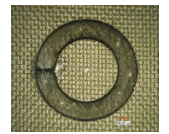

$1100 \mathrm{~mm} / \mathrm{s}$

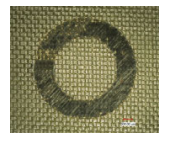

$\mathrm{HAZ}<10 \mu \mathrm{m}$

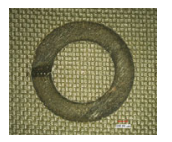

$\mathrm{HAZ}=33 \mu \mathrm{m}$
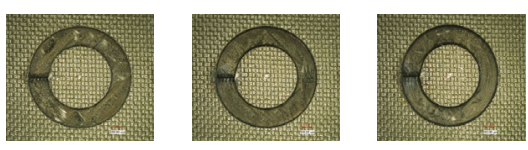

$\mathrm{HAZ}=57 \mu \mathrm{m}$ ablation depth increases for higher laser powers. More energy delivered to the machining zone at high power and low cutting speed due to longer interaction time and high number of pulses per spot, whereas high scanning speed reduces the energy input. Figure 5 shows the microscopic observations of the effects of scanning speed and laser power on HAZ and ablation depths.

Figure 6 shows the effect of laser power on the HAZ. It is seen that the HAZ is influenced by laser power and increases with the increase in laser power. Also at low scanning speeds, the HAZ is large compared to that at the higher scanning speed. It is clear that scanning speed plays a more dominating role in controlling the HAZ size.

The surface quality observations for different laser powers are shown in Fig. 7. The minimum HAZ $(<10 \mu \mathrm{m})$ obtained on the top surface at a low laser power $(6 \mathrm{~W})$, whereas for the $25 \mathrm{~W}$ lasers power, the HAZ was $56 \mu \mathrm{m}$. All the experiments to investigate the effect of laser power on milling quality were done using 50 passes continuously without allowing for short dwell time between the passes. The HAZ could be reduced by permitting a short cooling time $(0.5-1 \mathrm{~ms})$ between the passes.

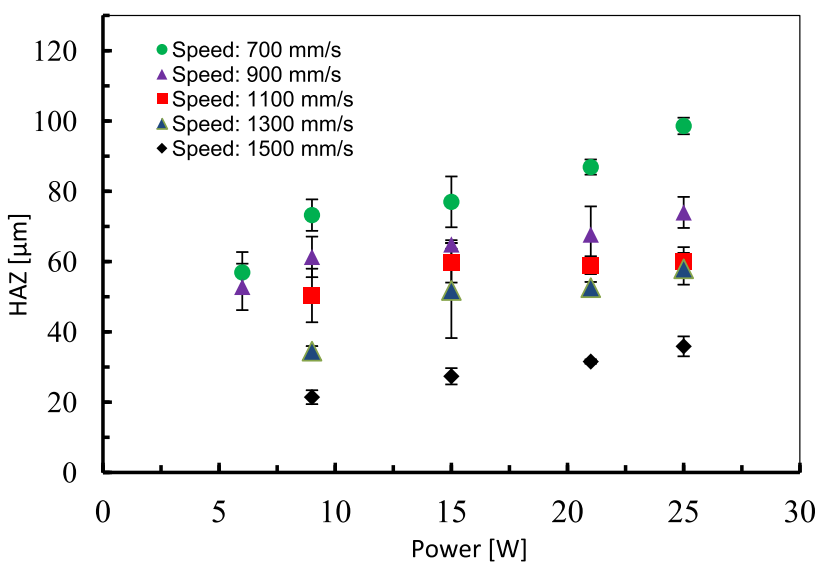

Fig. 6 Effect of laser power on HAZ at different scanning speed

\subsection{Effect of repetition rate on $\mathrm{HAZ}$}

The HAZ increases with the increase in repetition rate as shown in Fig. 8. A high repetition rate produces large thermal damages due to the increase in number of pulse and high pulse overlap per laser spot. 
Fig. 7 Thermal damage on the top surfaces at different powers; a $6 \mathrm{~W}$, b $9 \mathrm{~W}$, c $15 \mathrm{~W}$ and d $25 \mathrm{~W}$. Repetition rate: $0.5 \mathrm{MHz}$, speed: $1300 \mathrm{~mm} / \mathrm{s}$, number of passes: 50 , no dwell time
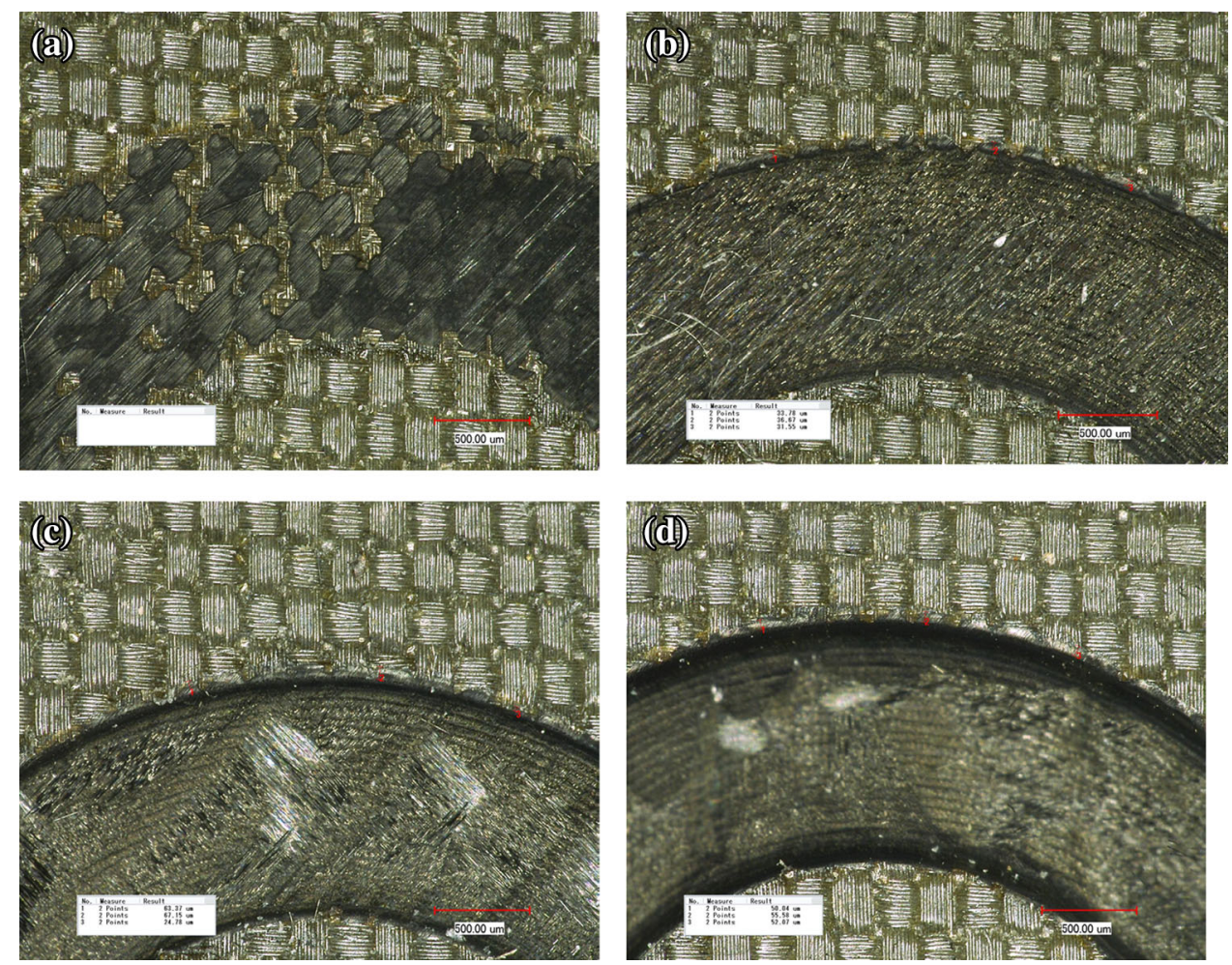

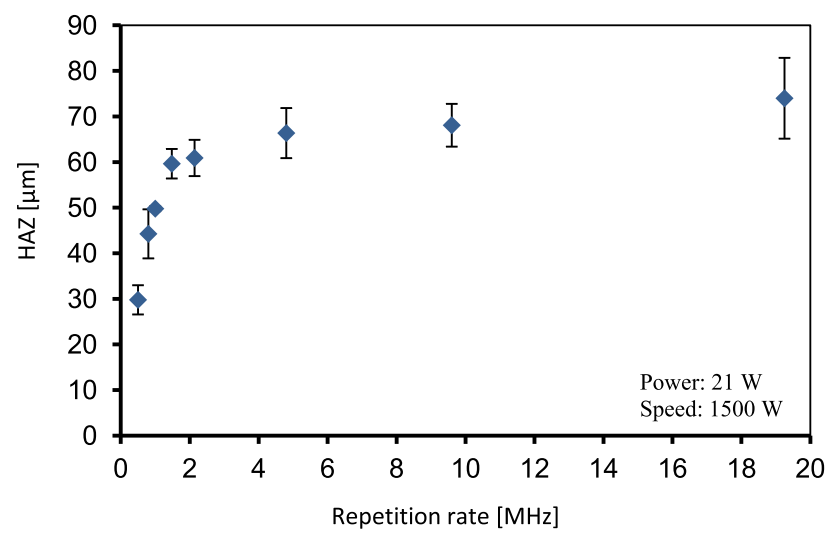

Fig. 8 Effect of repetition rate on HAZ

The high repetition rate delivers high number of pulses to the processing zone in a short time and restricts cooling time between the pulses. The high number of pulses delivers high energy to the processing region. The microscopic observations of the milling quality (HAZ) at different repetition rates are shown in Fig. 9. The better quality was obtained at a low repetition rate.

\subsection{Effect of ring spacing on thermal damages (HAZ) and ablation depth}

Figures 10 and 11 show the effect of rings spacing on the machine quality and ablation depth. It is clearly seen that the HAZ is improved by increasing the spacing between the rings. However, this reduces the ablation depth. The high quality is obtained by wider ring spacing due to less energy deposited in a unit area of the processing zone. Figures 12 and 13 show the microscopic observations of the effect of ring spacing. The larger spacing between rings produced good quality but low ablation depth and slower processing time. A ring spacing of $75 \mu \mathrm{m}$ produced the best consistency in terms of width of HAZ.

\subsection{Drilling of 0.3-, 1- and 2-mm-thick CRFP}

Figures 14, 15, 16 and 17 show results of trials to drill 0.3-, 1- and 2-mm-thick CFRP samples. The results show the drilling quality for the holes on both the entry and the exit sides. There was less thermal damage at the cutting edges where the matrix still covers most of the fibres near the drilled edge.

\subsection{Drilling 6-mm-thick CFRP composites}

The results in Figs. 18, 19, 20 and 21 show a 6-mm-diameter hole drilled in CFRP composites using the multiring strategy with a clear reduction in the HAZ on the entry side. The edge in Fig. 19b is sharp and no obvious fibres extruding out of the matrix. Also the polymer near the edge is not vaporised and is still holding and fills the gaps between the carbon fibres. The average measured HAZ at 
Fig. 9 Microscopic observations of effect of repetition rate on HAZ. a $0.5 \mathrm{MHz}$, b $1 \mathrm{MHz}$, c $4.8 \mathrm{MHz}, \mathbf{d} 19.25 \mathrm{MHz}$. Power: $21 \mathrm{~W}$, speed: $1500 \mathrm{~mm} /$ s, passes: 50
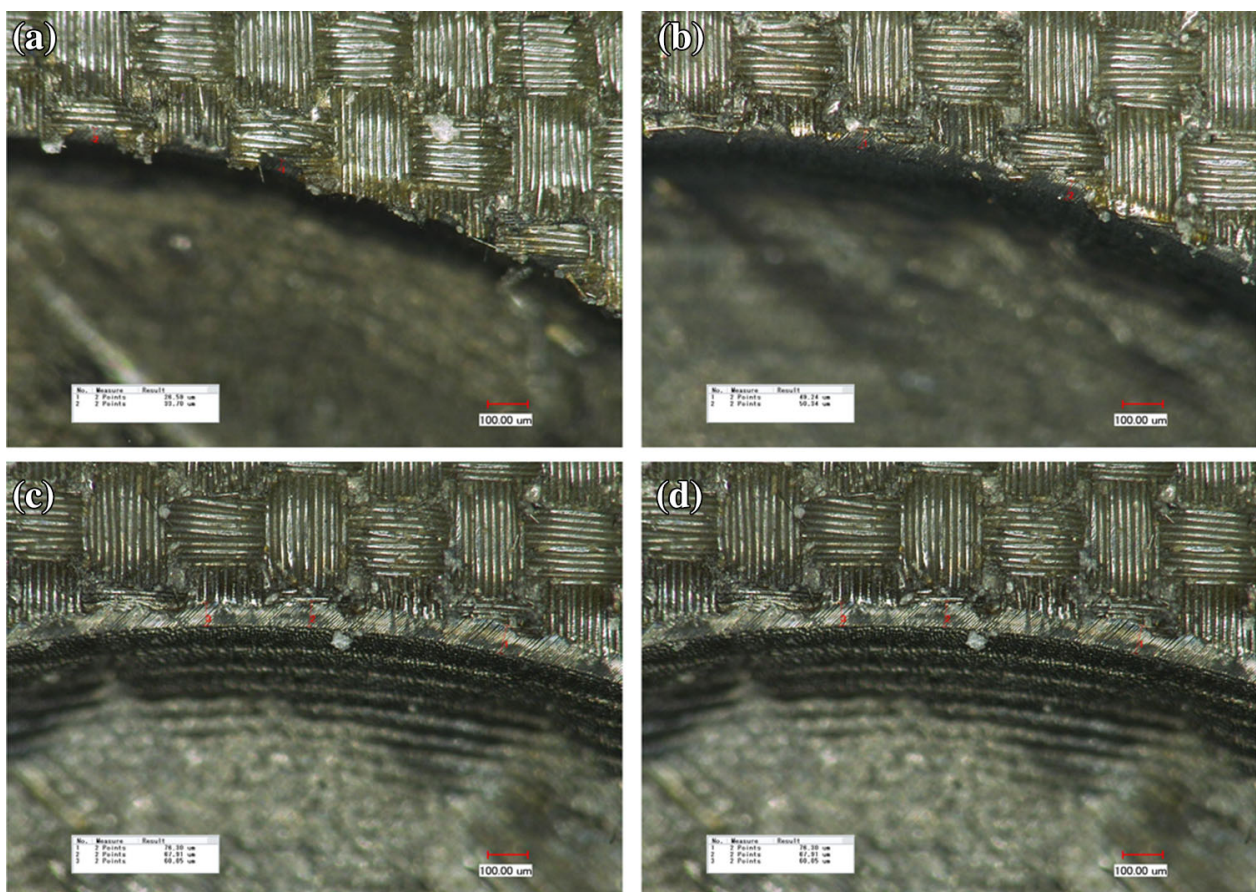

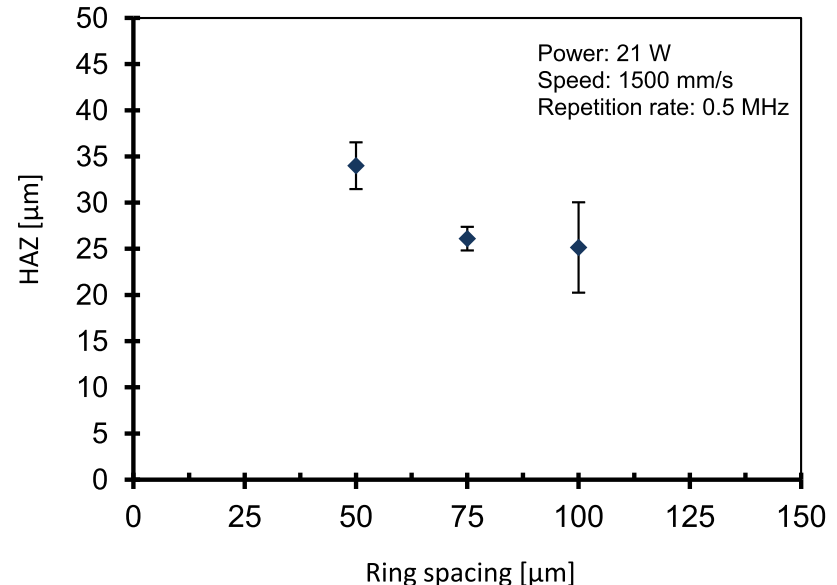

Fig. 10 Effect of ring spacing on HAZ

the top surface of sample was less than $25 \mu \mathrm{m}$, whereas under the surface there was no noticeable thermal damage observed as shown in Figs. 20 and 21. Figure 22 shows a taper cross section in the shape for the hole drilled. The angle is about $15.39^{\circ}$.

\section{Discussion}

The key challenge during laser processing of materials is reduction or elimination of HAZ. Using picosecond laser pulses reduces and eliminates the HAZ by shortening the laser-material interaction time and reducing the heat diffusion into the surrounding materials [23]. The high peak

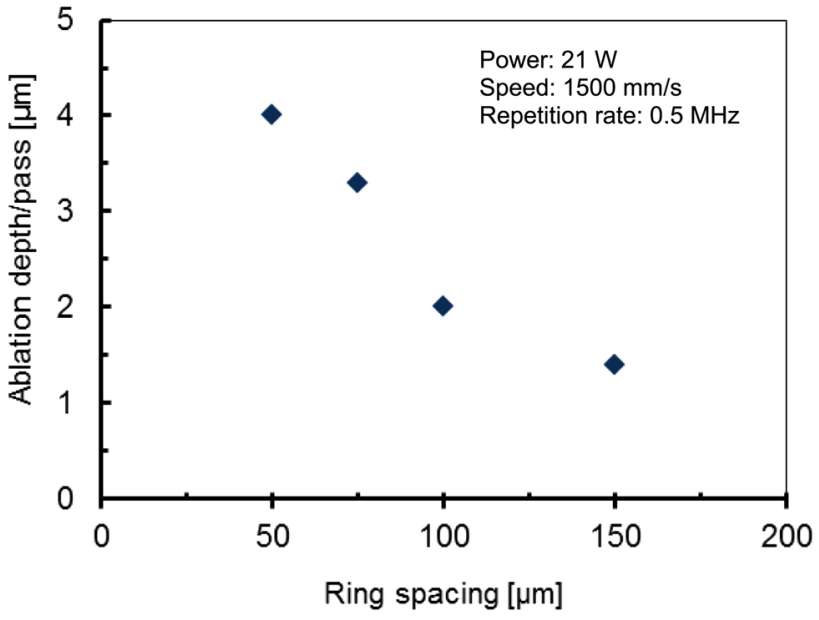

Fig. 11 Effect of ring spacing on ablation depth

power optioned due to short pulse duration in picosecond laser machining can rapidly heat the targeted material and lead to faster vaporisation of the material leaving no time for heat to conduct into the bulk. In short laser pulses, the laser radiated energy absorbed and stored by the free electrons for about $1 \mathrm{ps}$; then, the energy is converted into heat and transferred to the materials lattice leading to the ablation of target material [24]. During short picosecond laser processing (wavelength $1064 \mathrm{~nm}$ ) of CFRP composite, the laser energy is mainly absorbed by carbon fibres due to the higher absorbent of carbon fibre to the nearinfrared wavelength compared to the epoxy which is approximately transparent [25]. Despite the low photon 
Fig. 12 Effect of ring spacing on thermal damages; a $50 \mu \mathrm{m}$, b $75 \mu \mathrm{m}$, c $100 \mu \mathrm{m}$ and d $150 \mu \mathrm{m}$. Power: $21 \mathrm{~W}$, repetition rate: $0.5 \mathrm{MHz}$, speed: $1500 \mathrm{~mm} / \mathrm{s}$, passes: 50
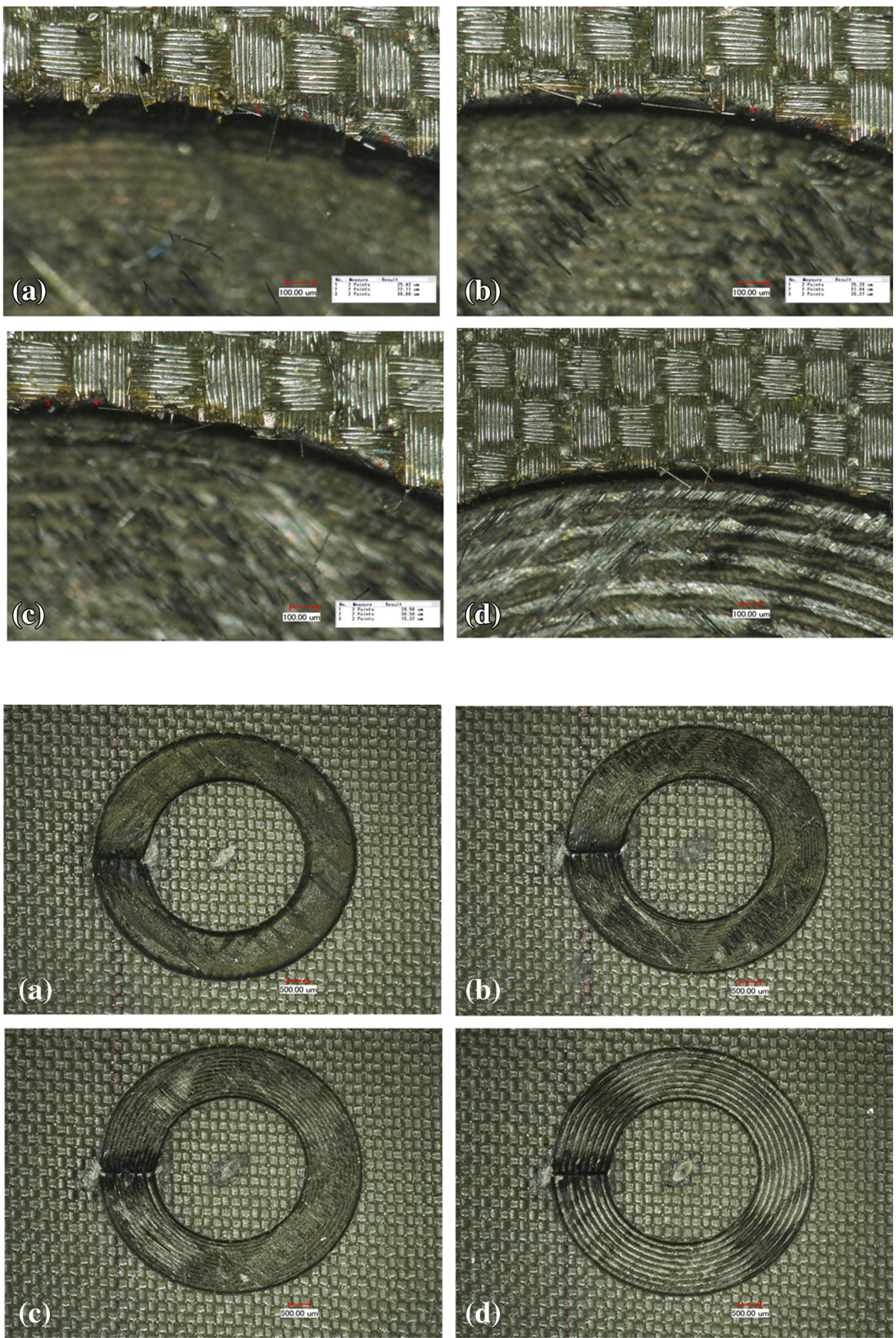

Fig. 13 Effect of ring spacing on ablation depth; a $50 \mu \mathrm{m}$ b $75 \mu \mathrm{m}$ c $100 \mu \mathrm{m}$ d $150 \mu \mathrm{m}$. Power: $21 \mathrm{~W}$, repetition rate: $0.5 \mathrm{MHz}$, speed: $1500 \mathrm{~mm} / \mathrm{s}$, passes: 50 energy of the laser used, the high peak intensity results in direct ablation of the materials, whereas some of the heat is conducted along the fibres due to the high thermal conductivity of the fibre $(50 \mathrm{~W} / \mathrm{m} \mathrm{k})$ compared to the epoxy resin $(0.1 \mathrm{~W} / \mathrm{m} \mathrm{k})$ and leads to evaporation of surrounding matrix. Furthermore, the multi-pass technique used in this work helps to slice the fibre into small pieces when machining perpendicular to the fibre direction. In this case, the heat accumulation raises the temperature between the laser traces. When this temperature is high enough to evaporate the matrix material, the epoxy around the fibres evaporates leaving the chopped carbon fibres unattached which then blown out by thermochemical force. Moreover, the multi-pass widens the kerf and allows for the plume, plasma and fragmented fibres to escape from the machined area allowing for the laser beam to reach the internal 
Fig. 14 Laser drilling of 0.3mm-thick CFRP; a entry side, b exit side. Power: $21 \mathrm{~W}$, repetition rate: $0.5 \mathrm{MHz}$, speed: $1500 \mathrm{~mm} / \mathrm{s}$, number of passes: 100, dwell time: $5 \mathrm{~s}$
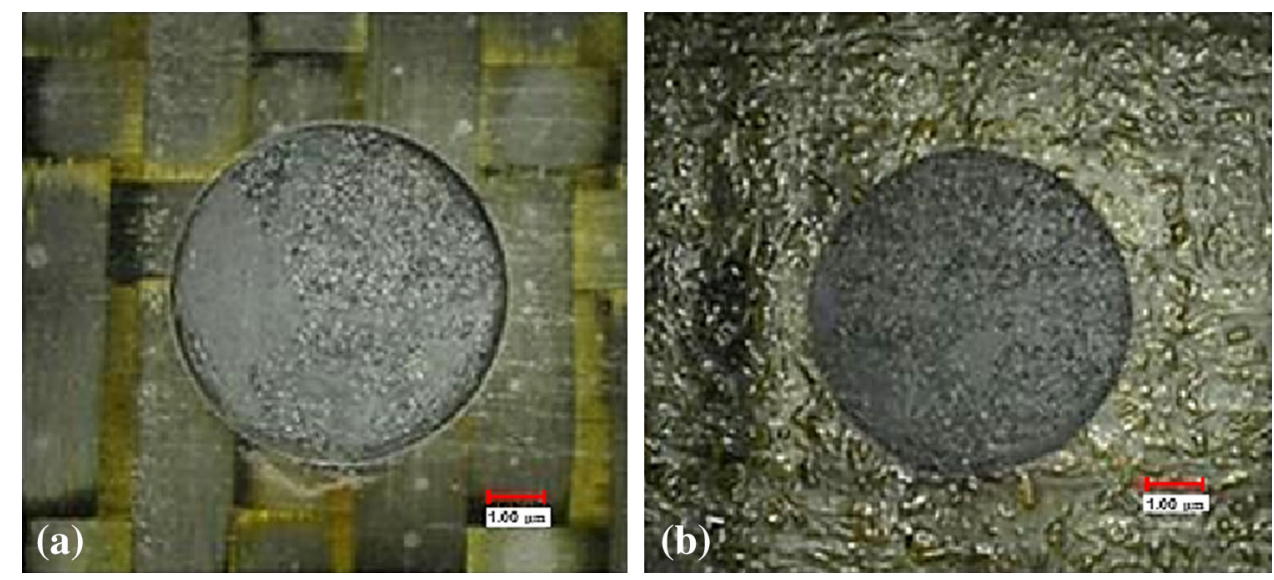

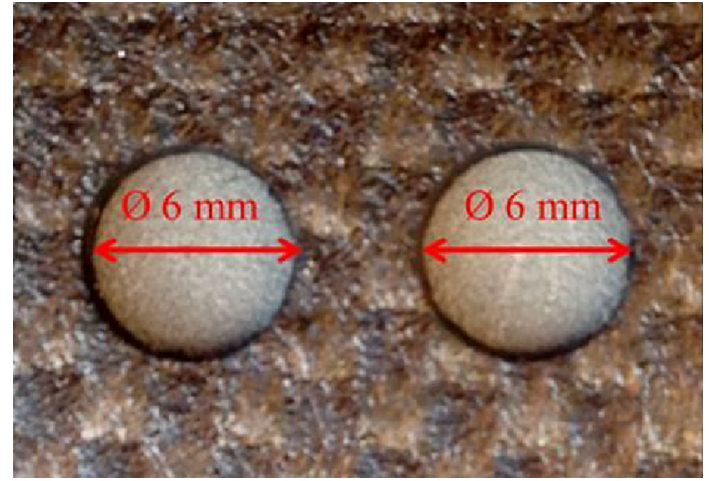

Fig. 15 Drilling of 1-mm-thick CFRP. Power: $40 \mathrm{~W}$, repetition rate: $0.5 \mathrm{MHz}$, speed: $1000 \mathrm{~mm} / \mathrm{s}$, number of passes: 200, dwell time: $2 \mathrm{~s}$

material and enhance the processing rate. This technique helps to reduce the thermal damage by blocking the heat conduction to the surrounding materials when cutting the outer ring first [9].

The cross-sectional views in Fig. 20 show taper walls of the drilled hole in which the hole diameters reduced as the machining depth increases. The reduction in the hole size at the bottom could be accredited to the less contribution of the energy reflected from the machined sides where the laser beam is absorbed by carbon fibre instead of reflected like metals resulting in less laser energy at the hole bottom, thereby reducing the hole size [26]. The reduction in the laser energy absorbed by the material as the depth increases due to plasma blocking is another reason for the taper shape [13]. Moreover, due to the higher thermal conductivity of CFRP, the heat generated in the machined area conducted to the surrounding material between the laser pulses results in less temperature at the zone sides than at the zone centre of the machined area; therefore, the central zone always ablated first due to the fast energy build-up at the central zone by incident pulses. In addition, the higher beam intensity at the centre of the Gaussian beam shape removes much material at the centre than at the side of the beam, leads to deeper cut at the central region and produces taper shape. Tilting the sample or offsetting the laser beam during a linear laser machining trial (Fig. 22) shows it is possible to eliminate the taper walls (Fig. 23) during laser hole drilling by tilting the laser beam using trepanning optics or 3D robotic laser head. Figure 5 shows that as the scanning speed increases, the HAZ was decreased. This could be attributed to the reduction in laser-material
Fig. 16 Microscopic observations of 1-mm-thick CFRP: a entry side, $\mathbf{b}$ exit side
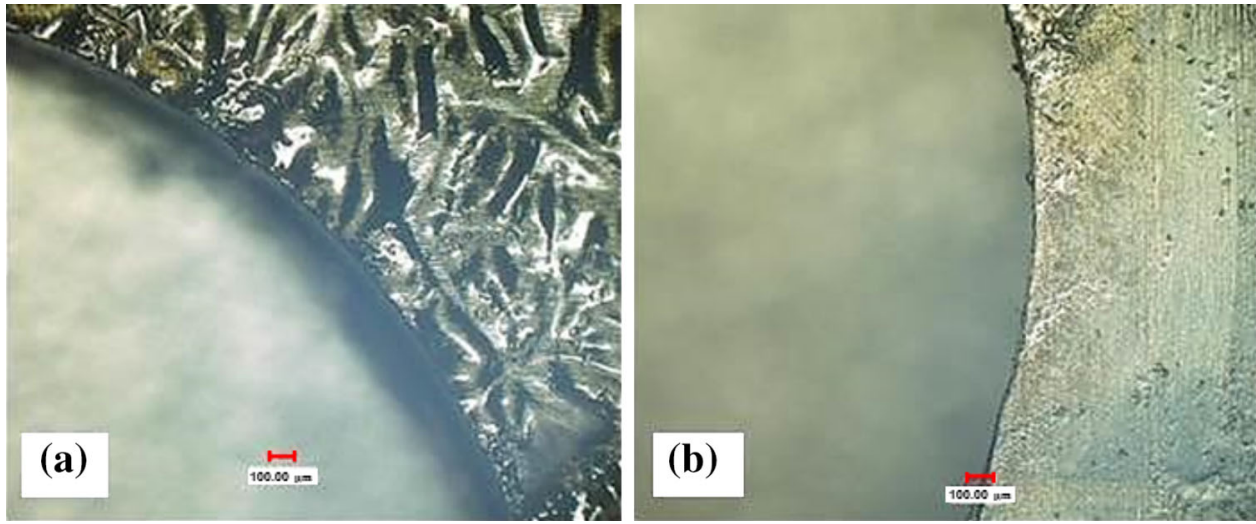

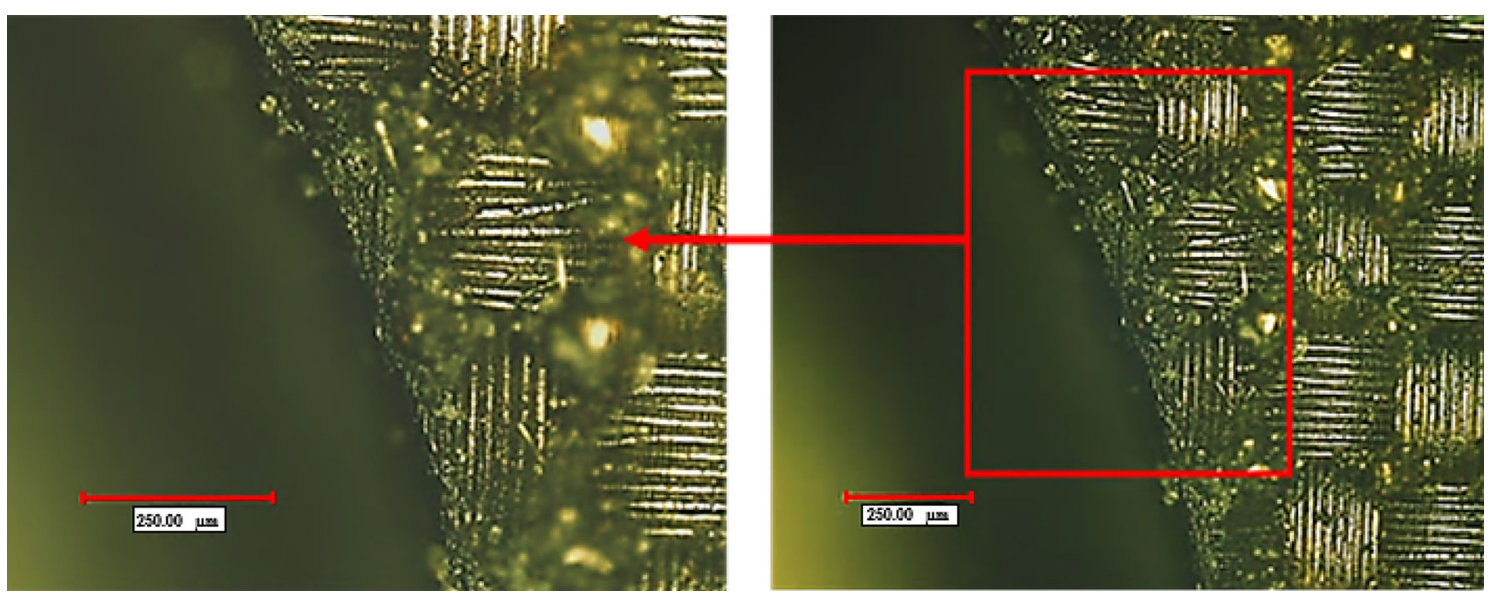

Fig. 17 Microscopic observations of 2-mm thick CFRP at different magnifications. Power: $21 \mathrm{~W}$, fluence: $0.3 \mathrm{~J} / \mathrm{cm}^{2}$, repetition rate: $0.5 \mathrm{MHz}$, speed: $2000 \mathrm{~mm} / \mathrm{s}$, number of passes: 500 , dwell time: $1 \mathrm{~s}$

Fig. 18 Hole of $6 \mathrm{~mm}$ diameter drilled in 6-mm-thick CFRP composites
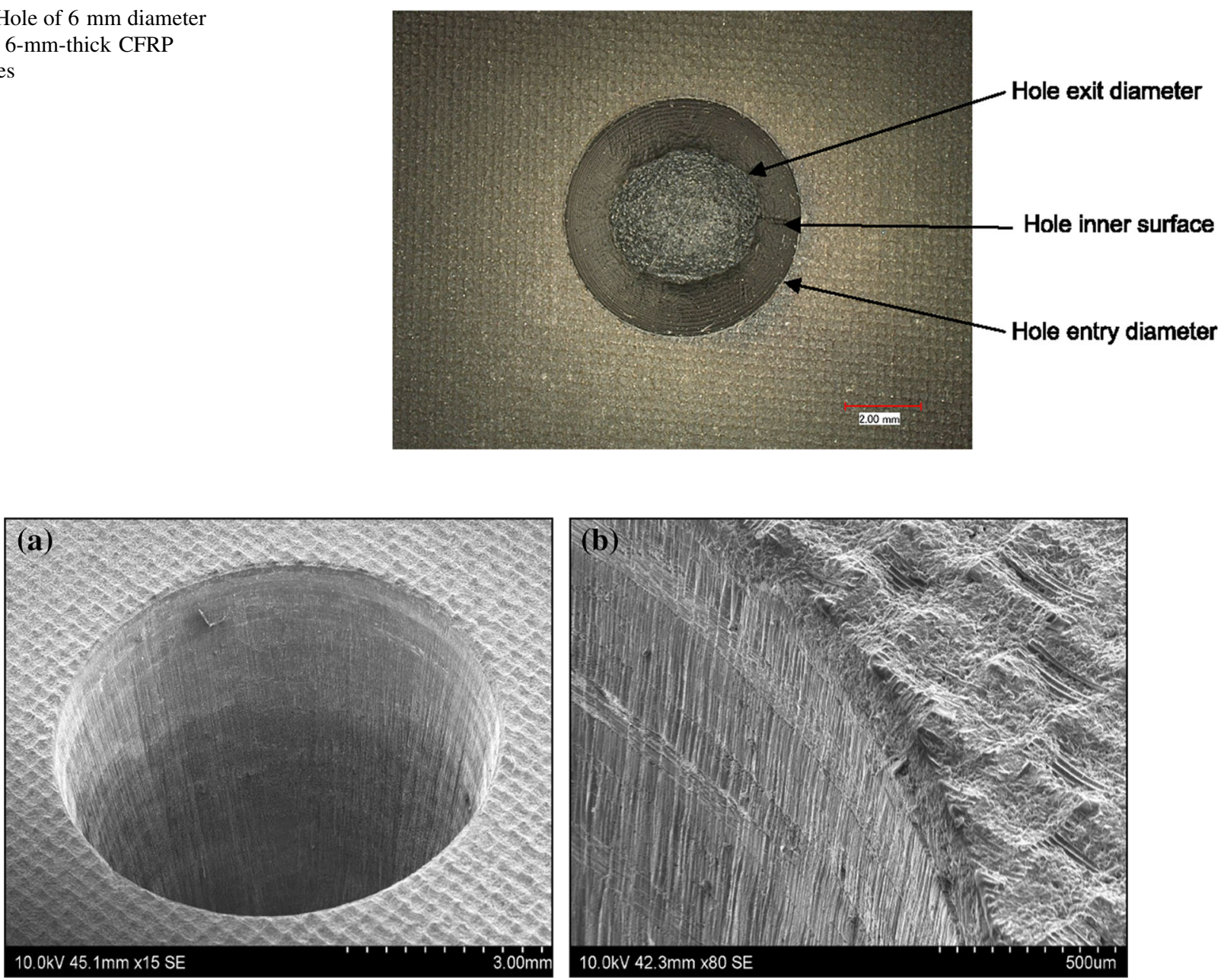

Fig. 19 SEM observations of CFRP drilled hole; a top surface b drilling edge

interaction time. At high scanning speed, the heat accumulation due to high pulses overlap at high repetition rates is reduced by which the laser energy delivered to the machining zone decreased. Increasing the repetition rate or reducing the scanning speed yields to large number of pulses on the same position, and thus, the heat delivered to 


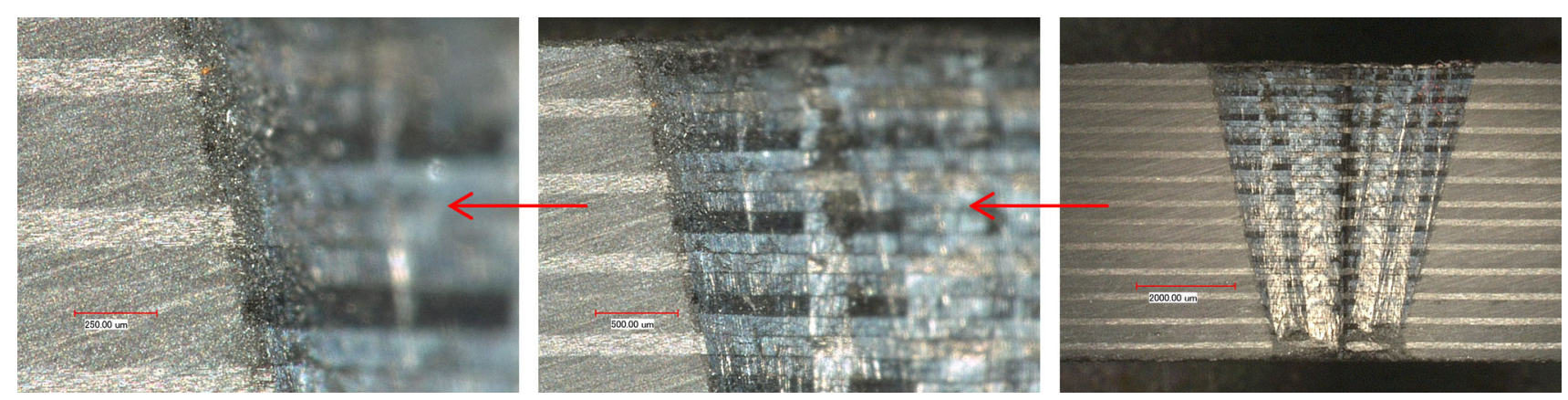

Fig. 20 Microscopic sectional view of drilled hole at different magnifications

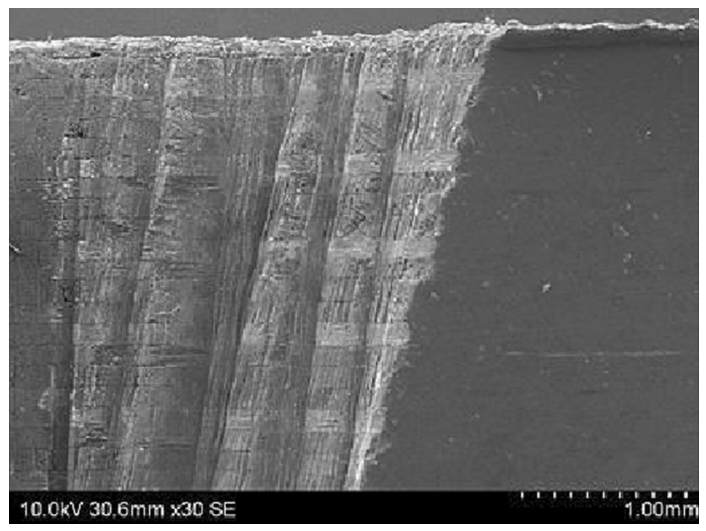

Fig. 21 SEM sectional view of 6-mm drilled hole the sample increases and leads to heat accumulation. For laser beam spot size of $125 \mu \mathrm{m}$, scanning speed of $2000 \mathrm{~mm} / \mathrm{s}$ and a repetition rate of $500 \mathrm{kHz}$, the number of laser pulses generated on the same position are 31 pulses. Also the low heat conduction between the ply stacks and in transverse direction of the fibre axis enhances the heat accumulation and results in higher thermal damage. Moreover, the non-homogeneous nature of the CFRP composite and the effect of fibre orientation direction on heat conduction produce nonuniform HAZ. Machining perpendicular to the fibre direction produces wider HAZ than machining parallel to fibre direction due to the higher thermal conductivity of CFRP along the fibres than transversely to the fibres [27].
Fig. 22 Taper elimination techniques; a sample tilting technique, $\mathbf{b}$ laser beam offsite technique; $X$ is laser beam offsite distance

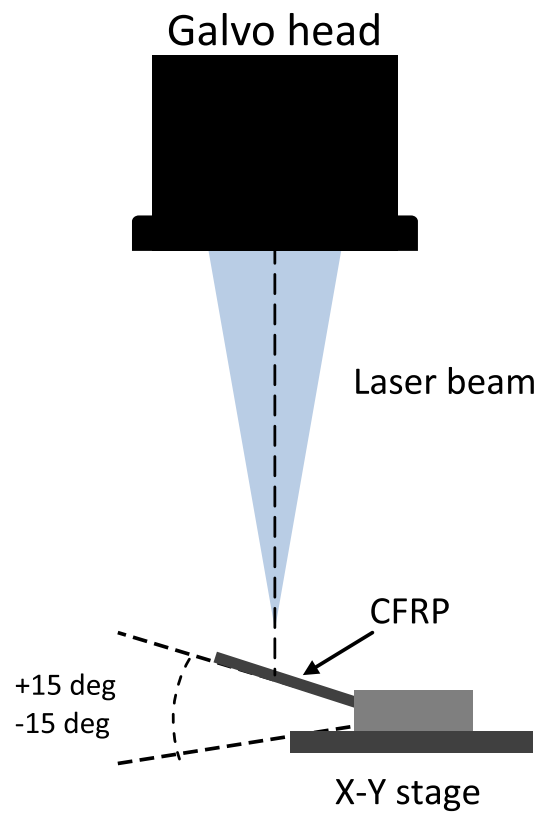

(a)

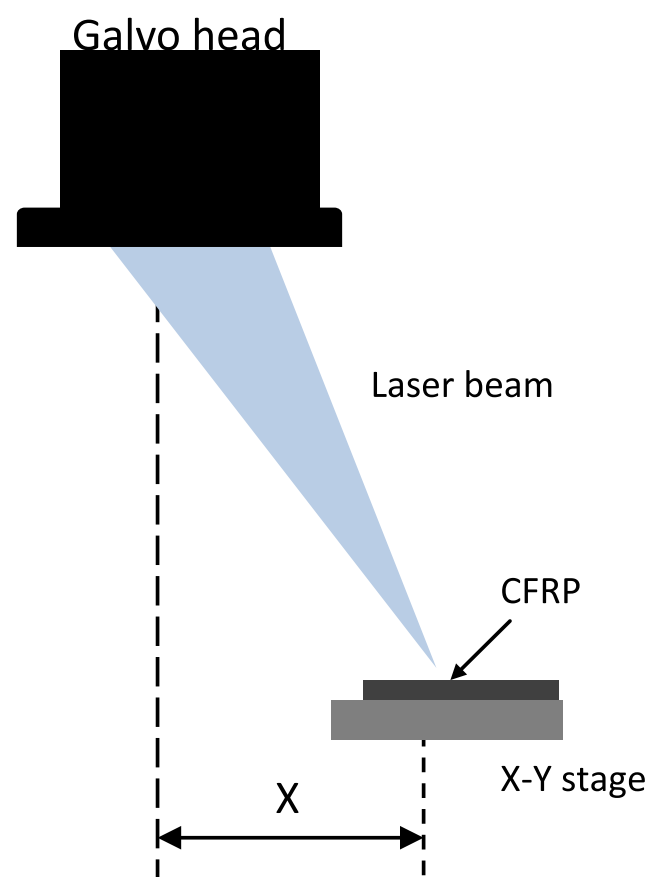

(b) 
Fig. 23 Microscopic observations of samples cross sections using: a tilting technique, b laser beam offsite technique
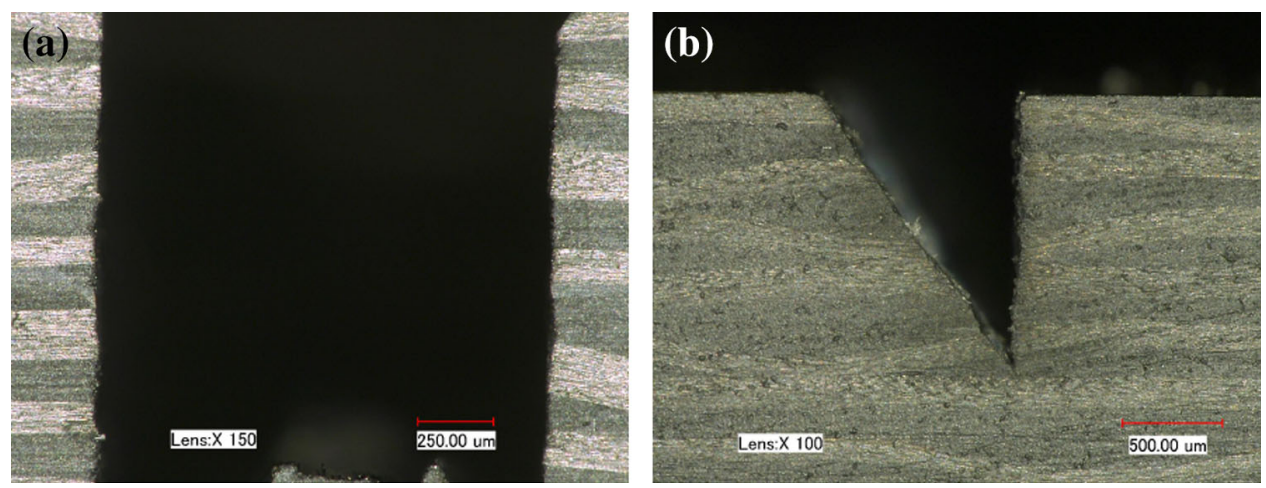

\section{Conclusion}

From this work, the following conclusions can be drawn:

1. The experimental study shows that the HAZ and ablation depths reduce as the laser power reduces and the scanning speed increases.

2. Holes with $6 \mathrm{~mm}$ diameter and $6 \mathrm{~mm}$ thickness of CFRP was drilled with high quality at a scanning speed of $2 \mathrm{~m} / \mathrm{s}$. HAZ is $25 \mu \mathrm{m}$ at the entrance side, much smaller than previously reported results using nanosecond pulsed lasers. The holes produced in 6-mm-thick CFRP showed a taper angle about $15^{\circ}$. Also the processing time was quite long. It took about half an hour to break through this hole. Techniques to reduce taper were presented in this work.

3. High machining quality demands fast scanning speed for a given laser power.

Open Access This article is distributed under the terms of the Creative Commons Attribution 4.0 International License (http://crea tivecommons.org/licenses/by/4.0/), which permits unrestricted use, distribution, and reproduction in any medium, provided you give appropriate credit to the original author(s) and the source, provide a link to the Creative Commons license, and indicate if changes were made.

\section{References}

1. K.K. Chawla, Composite Materials, Science and Engineering. (Springer Science and Business Media, New York, 2012)

2. W.S. Lau, T.M. Yue, T.C. Lee, W.B. Lee, J. Mater. Process. Technol. 48, 199 (1995)

3. W.S. Lau, W.B. Lee, Mater. Manuf. Process. 6, 331 (1991)

4. J.P. Davim, P. Reis, Compos. Struct. 59, 481 (2003)

5. D. Herzog, P. Jaeschke, O. Meier, H. Haferkamp, Int. J. Mach. Tool Manu. 48, 1464 (2008)

6. W. Koenig, C. Wulf, P. Grass, H. Willerscheid, CIRP Ann. Manuf. Technol. 34, 537 (1985)

7. J.-D. Kim, E.-S. Lee, J. Mater. Process. Technol. 43, 259 (1994)

8. E. Uhlmann, G. Spur, H. Hocheng, S. Liebelt, C.T. Pan, Int. J. Mach. Tool Manuf. 39, 639 (1999)
9. Z. Li, H. Zheng, G. Lim, P. Chu, L. Li, Compos. A Appl. S. 41, $1403(2010)$

10. Z. L. Li, P. L. Chu, H. Y. Zheng, G. C. Lim, L. Li, S. Marimuthu, R. Negarestani, M. Sheikh, P. Mativenga, in Advances in Laser Materials Processing, ed. by J. Lawrence, J. Pou, D. K. Y. Low, E. Toyserkani (Woodhead Publishing, 2010), p. 136-177

11. J. Finger, M. Weinand, D. Wortmann, J. Laser. Appl. 25, 042007 (2013)

12. R. Negarestani, M. Sundar, M. Sheikh, P. Mativenga, L. Li, Z. Li, P. Chu, C. Khin, H. Zheng, G. Lim, Proc. Inst. Mech. Eng. B J. Eng. Manuf. 224, 1017 (2010)

13. J. Mathew, G.L. Goswami, N. Ramakrishnan, N.K. Naik, J. Mater. Process. Technol. 89-90, 198 (1999)

14. R. Negarestani, L. Li, H.K. Sezer, D. Whitehead, J. Methven, Int. J. Adv. Manuf. Technol. 49, 553 (2010)

15. C. Leone, N. Pagano, V. Lopresto, I. De Iorio, in Proceedings of 17th International Conference on Composite Materials-ICCM17, (2009)

16. H. Niino, Y. Kawaguchi, T. Sato, A. Narazaki, R. Kurosaki, M. Muramatsu, Y. Harada, K. Wakabayashi, T. Nagashima, Z. Kase, in SPIE Lase. (International Society for Optics and Photonics, 2013)

17. R. Negarestani, L. Li, Proc. Inst. Mech. Eng. B J. Eng. Manuf. 227, 1755 (2013)

18. A. Riveiro, F. Quintero, F. Lusquiños, J. del Val, R. Comesaña, M. Boutinguiza, J. Pou, Compos. A Appl. 43, 1400 (2012)

19. A. Wolynski, T. Herrmann, P. Mucha, H. Haloui, J. L'huillier, Phys. Procedia 12, 292 (2011)

20. C. Emmelmanna, M. Petersen, A. Goeke, M. Canisius, Phys. Procedia 12, 565 (2011)

21. A. Klotzbach, M. Hauser, E. Beyer, Phys. Procedia 12, 572 (2011)

22. M.J.J. Schmidt, D.K.Y. Low, L. Li, Appl. Surf. Sci. 186, 271 (2002)

23. N. Muhammad, D. Whitehead, A. Boor, W. Oppenlander, Z. Liu, L. Li, Appl. Phys. A Mater. 106, 607 (2012)

24. J. Meijer, K. Du, A. Gillner, D. Hoffmann, V.S. Kovalenko, T. Masuzawa, A. Ostendorf, R. Poprawe, W. Schulz, CIRP Ann. Manuf. Technol. 51, 531 (2002)

25. J. Stock, M.F. Zaeh, M. Conrad, Phys. Procedia 39, 161 (2012)

26. F.A. Al-Sulaiman, B.S. Yilbas, M. Ahsan, J. Mater. Process. Technol. 173, 345 (2006)

27. Z. Li, P. Chu, H. Zheng, G. Lim, L. Li, S. Marimuthu, R. Negarestani, M. Sheik, P. Mativenga, 27th International Congress on Applications of Lasers and Electro-Optics (Laser Institute of America, Temecula, CA, 2008) 